\title{
Finger stick blood test to assess post vaccination SARS-CoV-2 neutralizing antibody response against variants
}

\begin{abstract}
Sing Mei Lim ${ }^{1, \dagger}$, Hoi Lok Cheng ${ }^{1, \dagger}$ Huan $\mathrm{Jia}^{1, \dagger}$, Patthara Kongsuphol ${ }^{1, \dagger, \ddagger}$, Bhuvaneshwari D/O Shunmuganathan ${ }^{2}$, Ming Wei Chen ${ }^{3}$, Say Yong $\mathrm{Ng}^{1}$, Xiaohong $\mathrm{Gao}^{3}$, Shuvan Prashant Turaga ${ }^{4}$, Sascha P. Heussler ${ }^{4}$, Joyti Somani ${ }^{5}$, Sharmila Sengupta ${ }^{5}$, Dousabel MY Tay ${ }^{6}$, Megan E. McBee ${ }^{1}$, Barnaby E. Young 7,8,9, Paul A. MacAry ${ }^{2,10}$, Hadley D. Sikes ${ }^{1,6,{ }^{*}}$, Peter R. Preiser $^{1,6,{ }^{*}}$
\end{abstract}

\section{Authors' Affiliations:}

${ }^{1}$ Antimicrobial Resistance Interdisciplinary Research Group (AMR-IRG), Singapore-MIT Alliance in Research and Technology (SMART); \#03-10/11 Innovation Wing, 1 CREATE Way, Singapore 138602.

${ }^{2}$ Department of Microbiology and Immunology, Yong Loo Lin School of Medicine, National University of Singapore (NUS); 5 Science Drive 2, Blk MD4, Level 3, Singapore 117545.

${ }^{3}$ School of Biological Sciences (SBS), Nanyang Technological University (NTU); 60 Nanyang Dr, Singapore 637551.

${ }^{4}$ Attonics System Pte. Ltd. 10 Anson Road, \#12-01 International Plaza, Singapore 079903.

${ }^{5}$ National University Hospital (NUH); 5 Lower Kent Ridge Rd, Singapore 119074.

${ }^{6}$ Department of Chemical Engineering, Massachusetts Institute of Technology (MIT); 25 Ames Street, Building 66 Cambridge, MA 02139, USA.

\section{${ }^{7}$ National Centre for Infectious Diseases (NCID); 16 Jalan Tan Tock Seng, Singapore} 308442.

${ }^{8}$ Department of Infectious Diseases, Tan Tock Seng Hospital; 16 Jalan Tan Tock Seng, Singapore 308442.

${ }^{9}$ Lee Kong Chian School of Medicine; 59 Nanyang Drive Singapore 636921.

${ }^{10}$ Life Sciences Institute (LSI), National University of Singapore (NUS); \#05-02, 28 Medical Drive, Singapore 117456.

† SM, HC, HJ and PK contribute equally as co-first authors.

${ }^{\ddagger} \mathrm{PK}$ current affiliation is Thrixen Pte. Ltd.

* HDS and PRP are co-corresponding authors. Emails: sikes@mit.edu;

prpreiser@ntu.edu.sg. 
medRxiv preprint doi: https://doi.org/10.1101/2021.11.11.21266241; this version posted November 14,2021 . The copyright holder for this preprint (which was not certified by peer review) is the author/funder, who has granted medRxiv a license to display the preprint in All rights reserved. No reuse allowed without permission.

\section{ABSTRACT}

50 There is clinical need for a quantifiable point-of-care (PoC) SARS-CoV-2 neutralizing 51 antibody (nAb) test that is adaptable with the pandemic's changing landscape. Here, 52 we present a rapid and semi-quantitative nAb test that uses finger stick or venous 53 blood to assess the nAb response of vaccinated population against wild-type, alpha, 54 beta, gamma, and delta variant receptor binding domains. It captures a clinically 55 relevant range of $\mathrm{nAb}$ levels, and effectively differentiates pre-vaccination, post $1^{\text {st }}$ 56 dose and post $2^{\text {nd }}$ dose vaccination samples within 10 minutes. The data observed 57 against alpha, beta, gamma, and delta variants agrees with published results 58 evaluated in established serology tests. Finally, our test revealed a substantial 59 reduction in nAb level for beta, gamma, and delta variants between early BNT162b2

60 vaccination group (within 3 months) and later vaccination group (post 3 months). This 61 test is highly suited for PoC settings and provides an insightful nAb response in a post62 vaccinated population.

63

64 KEYWORDS

65 SARS-CoV-2; COVID19; neutralizing antibody; serology test; cellulose-pulldown assay; point-of-care test; humoral response against COVID19 variants. 
medRxiv preprint doi: https://doi.org/10.1101/2021.11.11.21266241; this version posted November 14,2021 . The copyright holder for this preprint (which was not certified by peer review) is the author/funder, who has granted medRxiv a license to display the preprint in

All rights reserved. No reuse allowed without permission.

68

69

70

\section{INTRODUCTION}

Highly transmissible SARS-CoV-2 variants such as B.1.1.7 (alpha) and B.1.617.2 (delta) have emerged and displaced the 'wildtype' virus and other variants within countries with high vaccination rates. With $38.9 \%$ of global population now vaccinated (as of 5th Nov 2021, live update from https://ourworldindata.org/covid-vaccinations), reports of breakthrough infections among vaccinees indicate the potential need for future vaccine boosters, particularly in vulnerable populations ${ }^{1-3}$. A rapid, easy to use Point-of-Care ( $\mathrm{PoC}$ ) test that measures the level of immune protection against SARSCoV-2 in both recovered as well as vaccinated individuals over time would be an important tool in guiding public health policy. Currently, standard viral neutralization test (VNT) and pseudovirus neutralization test (pVNT) have played critical roles in evaluating protective immunity, however their use is limited due to the need for BSL2 or BSL3 laboratory facilities, extended experimental time and relevant expertise. Moreover, the reproducibility varies depending on cell type, virus/pseudovirus generation, experimental protocol, and detection method ${ }^{4,5}$. While ELISA-based surrogate neutralization test can provide reliable information on immune protection, it requires skilled operators and dedicated facilities that are difficult to integrate into PoC testing ${ }^{6,7}$. PoC lateral flow tests are currently limited, as they either detect total immunoglobulin level which is not a reliable indicator for immune protection or only provide qualitative assessment ${ }^{8,9}$. The availability of a quick and accurate PoC nAb test to track vaccination induced immune responses especially against variants at both the population as well as individual level would be a valuable tool in enabling public health authorities to manage breakthrough infections and to develop an effective booster vaccination strategy for more vulnerable individuals.

We previously developed a rapid paper-based SARS-CoV-2 neutralization assay known as cellulose pulled-down virus neutralization test (cpVNT) that detects SARSCoV-2 neutralizing antibody ( $\mathrm{nAb}$ ) in plasma or serum within 10 minutes ${ }^{10}$. The principle of cpVNT is based on the complex formation between the receptor binding domain (RBD) of the SARS-CoV-2 and the angiotensin converting enzyme II receptor (ACE2) of the host cell. The RBD is fused with cellulose binding domain (RBD-CBD) to enable capture by cellulose paper while ACE2 is conjugated with reporting molecules for signal generation. The presence of $n A b$ in the sample disrupts RBD$\mathrm{CBD} / \mathrm{ACE} 2$ complex formation leading to a reduction in the overall signal detected. To 
medRxiv preprint doi: https://doi.org/10.1101/2021.11.11.21266241; this version posted November 14,2021 . The copyright holder for this preprint (which was not certified by peer review) is the author/funder, who has granted medRxiv a license to display the preprint in

All rights reserved. No reuse allowed without permission.

102

103

104

105

106

107

108

109

110

111

112

113

114

115

116

117

118

119

120

121

122

123

124

125

126

127

128

129

130

131

132

133

134

135

develop a PoC nAb detection test, we improved our cpVNT assay enabling it to be used directly on whole venous or capillary blood including finger stick blood samples. This bypasses the requirement for extensive sample processing or a phlebotomist. Comparison of this modified cpVNT test with established pVNT as well as an ELISAbased assay showed high degree of concordance. Importantly, the modified cpVNT test can be easily adapted for the rapid evaluation of nAb responses to SARS-CoV2 variants among vaccinated population, providing critical insights into changes in nAb responses to vaccine types, variant mutations, and time post vaccination.

\section{RESULTS}

\subsection{Rapid detection of SARS-CoV-2 neutralization antibody in blood using modified cpVNT}

To adapt the previous cpVNT for the analysis of whole blood PoC diagnostic samples it was important to change the enzyme/substrate-based reporter system of HRP/TMB as well as the overall assay workflow. The two key modifications introduced are (i) the change to a fluorescent reporter molecule and (ii) sequential incubation steps (Fig. 1A, S1A). For this, we selected Alexa Fluor ${ }^{\circledR} 594$ as the reporter in consideration of its high quantum yield, excellent photostability, and minimal interference with blood. In addition, to improve the test performance and minimize the non-specific background from whole blood sample, we altered the cpVNT workflow to a two-step incubation, as compared to the one-step incubation reported previously. First, $20 \mu \mathrm{L}$ of blood sample was mixed with $20 \mu \mathrm{L}$ of $10 \mathrm{nM}$ RBD-CBD for 3 minutes before adding $40 \mu \mathrm{L}$ of $5 \mathrm{nM}$ fluorescence labelled human ACE2 (ACE2-AF594) and incubating for additional 5 minutes at ambient temperature. Equal amount of the final $80 \mu \mathrm{L}$ mixture was then applied to the cassette's test and control spot respectively followed by one washing step with $40 \mu \mathrm{L}$ of PBS for each spot (Fig. 1A \& B). The additional 3 minutes incubation step introduced in this study allowed $\mathrm{nAb}$ in the blood sample to effectively interact with RBD-CBD prior to exposure to ACE2 (Fig. S1 B \& C).

Since the presence of nAb is inversely related to the fluorescence intensity, a control reaction is necessary to verify the reagent functionality, as the loss of signal should only be due to the presence of nAb. Therefore, we pre-immobilized the control spot with $5 \mu \mathrm{L}$ of $5 \mu \mathrm{M}$ of RBD-CBD on the cellulose paper to capture ACE2-AF594 free from RBD-CBD/ACE2-AF594 complex and produce high level of fluorescent signal 
medRxiv preprint doi: https://doi.org/10.1101/2021.11.11.21266241; this version posted November 14,2021 . The copyright holder for this preprint (which was not certified by peer review) is the author/funder, who has granted medRxiv a license to display the preprint in

All rights reserved. No reuse allowed without permission.

136 regardless of the level of $n A b$ present in the blood (Fig. 1A, S1 D). A portable

137 fluorescent reader, Atto Testbed produced by Attonics Systems Pte. Ltd., Singapore

138 is customized to allow the detection of fluorescence signal under a PoC setting. The

139 reader excites the fluorophores using LED light. The emitted fluorescent intensity is

140 then detected using a silicon avalanche photodiode and reported as a voltage change

141 in $\mathrm{mV}$ unit. This voltage output $(\mathrm{mV})$ can be converted to percentage of blocking

142 according to Equation 1:

To evaluate this new test format, we made a series of contrived blood samples by spiking $1,5,10,25,50$ and $100 \mathrm{nM}$ of mouse monoclonal SARS-CoV-2 nAb into a blood prepared with pre-SARS-CoV-2 pandemic plasma and washed red blood cells.

149 The assay demonstrated an IC 50 of $3.38 \mathrm{nM}$ nAb using blood as sample matrix (Fig.

$1501 C \& D)$.

151

\subsection{Evaluation of post vaccination nAb responses using modified cpVNT.}

Modified cpVNT relies on the reduction of fluorescent signal in response to neutralizing antibodies competing with labelled ACE2. Two important fluorescent signals contribute to the determination of the signal dynamic range and $\mathrm{nAb}$ result interpretation, (i) the maximum fluorescence intensity obtained from negative control (NC) samples with no nAb (pre-vaccination, Pre-Vac samples); this value was used to set a reference point for calculation of blocking percentage in the presence of $n A b$ and (ii) non-specific background fluorescence observed from the test when RBD-CBD was absent from the reaction; this value was used to draw a baseline between specific and non-specific signals (see Equation 1). The NC value was defined by the median of

162 fluorescence intensity measured from 60 Pre-Vac blood samples in triplicates (Fig $163 \mathrm{~S} 2 \mathrm{~A}$ ), while the baseline value was the median of triplicate reads from 31 blood samples regardless of vaccination status when RBD-CBD was absent (Fig S2B). With this approach, the NC value using two independent batches of ACE2-AF594 resulted in a median fluorescence intensity of $1141 \mathrm{mV}$ (Table S1 and Fig S2A) while the baseline signal had a median intensity value of $230 \mathrm{mV}$ (Fig S2B). To calculate the 
medRxiv preprint doi: https://doi.org/10.1101/2021.11.11.21266241; this version posted November 14,2021 . The copyright holder for this preprint (which was not certified by peer review) is the author/funder, who has granted medRxiv a license to display the preprint in

All rights reserved. No reuse allowed without permission.

168

169

170

171

172

173

174

175

176

177

178

179

180

181

182

183

184

185

186

187

188

189

190

191

192

193

194

195

196

197

198

199

200

201

percentage of blocking based on the nAb levels of individual, we then applied the NC as well as baseline value to formulate Equation 1.

Once NC and the baseline were established, the nAb levels that block RBD and ACE2 interaction were measured in 170 blood samples using modified cpVNT at different stages of vaccination: pre-vaccination (Pre-Vac), 1-2 weeks post $1^{\text {st }}$ dose (P1 1-2W), 3-6 weeks post $1^{\text {st }}$ dose (P1 3-6W) and 3-16 weeks post $2^{\text {nd }}$ dose (P2). The Pre-Vac $(n=36)$ group's percent blocking was measured with a median of $1.96 \%$, this number increased to $14.3 \%$ in P1 1-2W group $(n=10)$ and P1 3-4W group at 36.5\% $(n=50)$. Lastly, we observed $89.1 \%$ for $\mathrm{P} 2$ samples ( $\mathrm{n}=74$ ) (Fig. 2A). A similar trend was observed when grouping the samples into individuals vaccinated with either BNT162b2 (Fig 2B) or mRNA-1273 (Fig 2C). The negative value of percent blocking observed in the Pre-Vac and P1 1-2W was likely due to viscosity variation among blood samples that could interfere with the binding kinetics of RBD-CBD with cellulose paper in the assay. Overall, the data showed a significant difference between Pre-Vac and P1 3-6W samples across the two different types of vaccines, i.e. BNT162b2 $(p<0.05)$ and mRNA-1273 $(p<0.001)$ (Fig 2B \& C). There was also a significant difference $(p<0.05)$ in median percent blocking for P1 3-6W group when compared between BNT162b2 recipients (23.4\%, $\mathrm{n}=30)$ and mRNA-1273 recipients $(51.2 \%$, $\mathrm{n}=20$ ) (Fig 2D). However, in P2 samples, both vaccines show comparable median percent blocking at $84.5 \%$ for BNT162b2 and 90.9\% for mRNA-1273 recipients (Fig 2B \& $C$ ). Mapping of the $\mathrm{nAb}$ response in 22 individuals who received either BNT162b2 or mRNA-1273 showed differential responses at P1 phase (Fig 2E). Both vaccines induced a heterogeneous though elevated response in all individuals tested as early as week 2 post first dose of vaccine.

\subsection{Modified cpVNT can detect wide range of nAb activities comparable to sVNT} and pVNT.

We used the WHO International Standard for anti-SARS-CoV-2 immunoglobulin (20/136) and Reference Panel (20/268) to assess the detection range of modified cpVNT and to better interpret the clinical data we have measured ${ }^{11}$. The International Standard comprising of plasma sample with assigned $1000 \mathrm{IU} / \mathrm{mL} \mathrm{nAb}$ activity resulted in $96.7 \%$ blocking in our modified cpVNT (Fig 3A). This percent blocking corresponded to the value observed from subjects in the P2 vaccination group (Fig. 2A). The Mid- 
medRxiv preprint doi: https://doi.org/10.1101/2021.11.11.21266241; this version posted November 14,2021 . The copyright holder for this preprint (which was not certified by peer review) is the author/funder, who has granted medRxiv a license to display the preprint in

All rights reserved. No reuse allowed without permission.

202

203

204

205

206

207

208

209

210

211

212

213

214

215

216

217

218

219

220

221

222

223

224

225

226

227

228

229

230

231

232

233

234

titre and Low-titre plasma from WHO Reference Panel with $210 \mathrm{IU} / \mathrm{mL}$ and $44 \mathrm{IU} / \mathrm{mL}$ $\mathrm{nAb}$ activity respectively were measured with $66.7 \%$ blocking (Mid) and $34.9 \%$ blocking (Low) in the modified cpVNT (Fig 3A). This showed that the test can produce a dose dependent response that captures the clinical range of nAb activity in plasma in under 10 minutes assay time. Since plasma represents approximately 55\% of whole blood, the percent blocking test results in plasma samples was expected to be higher than that of whole-blood due to the lack of erythrocytes. To correlate the percent blocking in the WHO standard and reference panel plasma to corresponding whole blood, we analyzed 30 matching samples of blood and plasma in the modified cpVNT. We found that the percent blocking in blood samples is approximately 0.87 times of that in plasma samples assuming the relationship between the two sample types are linear (Fig 3B). We observed that the overall median percent blocking in Pre-Vac samples was found below $30 \%$ blocking in modified cpVNT using blood as matrix (Fig 2A). It corresponds to $44 \mathrm{IU} / \mathrm{mL}$ neutralizing antibody activity which is close to the estimated protective neutralization against SARS-CoV-2 of approximately of $54 \mathrm{IU} / \mathrm{mL}$ by Khoury et al.'s predictive model ${ }^{12}$ (Fig 3B). Hence, 30\% blocking which correlates to $44 \mathrm{IU} / \mathrm{mL}$ was set as the cut-off value for the modified cpVNT to compare its performance with other neutralization tests (Fig 3B). Our test showed 81.5\% sensitivity ( $\mathrm{Cl}$ 61.9-93.7\%) and 100\% specificity ( $\mathrm{Cl}$ 81.5-100\%) when compared with the commercially available sVNT Genscript $\mathrm{CPass}^{\mathrm{TM}}$ (Fig 3C). Meanwhile, as compared to the lab based pVNT test, the modified cpVNT showed $100 \%$ sensitivity (Cl 47.8 - 99.9\%) and 66.7\% specificity (Cl: 38.4 - 88.2\%) (Fig 3D). For reference, the WHO plasma of nAb activity at $1000 \mathrm{IU} / \mathrm{mL}, 210 \mathrm{IU} / \mathrm{mL}$ and $44 \mathrm{IU} / \mathrm{mL}$ when performed with sVNT cPass yielded $94 \%, 78 \%$ and 19\% inhibition respectively (Table S3). The lower specificity and sensitivity relative to ELISA and pVNT can be attributed to the difference in sample type (whole blood vs plasma/serum) and different assay procedures.

To ensure that the modified cpVNT is suitable for PoC setting with finger stick blood, we assessed the correlation of $\mathrm{nAb}$ detected in venous vs finger-stick blood sample matrix. A total of 46 matched pairs from Pre-Vac, P1 and P2 samples show a high linear correlation between the two blood sample types, with a Pearson $r$ value of 0.9758 ( $p$ value $<0.001$ ) and an $\mathrm{R}^{2}$ of 0.9523 (Fig S2C). This demonstrates the suitability of our modified cpVNT for PoC deployment, as only $20 \mu \mathrm{L}$ of finger-stick 
medRxiv preprint doi: https://doi.org/10.1101/2021.11.11.21266241; this version posted November 14,2021 . The copyright holder for this preprint (which was not certified by peer review) is the author/funder, who has granted medRxiv a license to display the preprint in

All rights reserved. No reuse allowed without permission.

blood samples is necessary to measure the nAb response in 10 minutes. Moreover, the outcomes are comparable to established lab-based neutralization tests.

\subsection{Assessment of post-vaccinated nAb percent blocking against SARS-CoV-2 variant RBDs}

Given the emergence of several SARS-CoV-2 variants and the accompanying uncertainty of the effectiveness of vaccine-induced nAbs against them, there has been burgeoning interest in evaluating $n A b$ responses to variant RBDs. In light of this, we first recombinantly produced 4 variants of concern (VOCs): alpha B.1.1.7, beta B.1.351, gamma P.1, delta B.1.167.2 and 5 variants of interest (VOls): kappa B.1.167.1, epsilon B.1.427/B.1.429, delta plus AY.1, eta B.1.525, lambda C.37 fused with $\mathrm{CBD}$ and evaluate their binding activity with ACE2 using Biolayer-Interferometry (BLI) (Fig. S3 \& S4A). These variants contain mutations in the RBD region, which may reduce the binding affinities of antibodies generated against the wildtype protein and/or increase ACE2 receptor binding ${ }^{13}$. We found that the binding affinity of alpha, beta, gamma, and delta are higher than that of wildtype (WT), especially gamma that showed a 3 -fold increase ( $4.3 \mathrm{nM})$ in binding affinity comparing to wild-type (12.7 nM) consistent with previous report ${ }^{13,14}$ (Table 1). Furthermore, our result supports published data that the N501Y mutation in the alpha, and gamma variants of RBD contributes to the slow off-rate of the complex ${ }^{15}$ (Table 1). Meanwhile T478K appears to promote fast complex formation based on comparison among delta, kappa, epsilon, and a delta plus variant that shared the L452R mutation (Table 1). We engineered a hypothetical RBD variant containing N501Y, T478K mutation and annotated it as 'AD' (alpha-delta) variant that is speculated to have fast on-rate and slow off-rate with ACE2. This hypothetical variant confirmed our hypothesis where it binds ACE2 with the highest binding affinity (KD of $3 \mathrm{nM}$ ) among the 10 variants (Table 1 ). Next, we assess the activity of these RBD-CBD variants on the modified cpVNT with Pre-Vac blood. Although variants with high affinity to ACE2 showed increased fluorescence intensity than WT RBD-CBD in the modified cpVNT assay at the same reagent concentration, ie. alpha (1.8-fold), beta (1.6-fold), gamma (2.1-fold), delta (1.3-fold), the correlation is not direct. As we observed variant RBD-CBDs epsilon and lambda still generate comparable signal as WT despite the lower ACE2 binding affinity, while $A D$ variant showed merely 1.6 -fold increase in signal despite binding ACE2 strongly (Fig. S4A). 
medRxiv preprint doi: https://doi.org/10.1101/2021.11.11.21266241; this version posted November 14,2021 . The copyright holder for this preprint (which was not certified by peer review) is the author/funder, who has granted medRxiv a license to display the preprint in

All rights reserved. No reuse allowed without permission.

268 Besides the binding kinetics, the capture rate of RBD-CBD on the cellulose paper and possible avidity of the different RBD-variants on ACE2 could contribute to the effect.

We then tested the 4 VOCs: RBD-CBD alpha, beta, gamma, and delta with 33 blood samples from participants within 3 months of completing vaccination. There were considerable variations in the $\mathrm{nAb}$ responses to the different variants. The nAb percent blocking against beta and gamma variants being reduced significantly to $72.4 \%$ and $70.1 \%$, while the percent blocking reduced only minimally to $87.2 \%$ and $91.9 \%$ for alpha and delta respectively as compared to WT (95.6\%) (Fig 4A). These were in line with previous reports using pVNT and VNT, whereby neutralization of beta and gamma variants had considerable reduction for both mRNA vaccines ${ }^{16-18}$. About 91.8\% nAb blocking was observed against the engineered $A D$ variant even though the RBD-CBD variant binds strongly to ACE2, suggesting that vaccine induced nAb can outcompete stronger interaction (Fig S4B). While this data indicated a heterogenous response it was important to evaluate whether our test was able to stratify response in relation to the different vaccines used. The median percent blocking for BNT162b2 recipients against alpha was 78\% ( $p<0.01)$ and delta was $89.2 \%(p=n . s$.$) as compared to WT$ (94.8\%). (Fig 4B). The most substantial reductions of $n A b$ response were observed with beta and gamma variants reaching $55.7 \%$ and $49.6 \%$ blocking respectively among BNT162b2 recipients (Fig 4B). In the cohort of mRNA-1273 recipients, we observed reduction to $87.5 \%$ with beta variant $(p<0.0001)$ and $80.5 \%$ with gamma variant $(p<0.0001)$.

Next, we also examined and compared the percent blocking of nAb in whole-blood samples from participants within three months or greater than three months after completion of vaccination against WT and 4 VOCs RBD-CBD. Only samples from BNT162b2 recipients were available to us for the greater than three months cohort as it was the first vaccine rolled-out in the Singapore national vaccination program. There was a modest drop of nAb percent blocking from $96 \%$ to $68 \%(28 \%, p<0.0001)$ observed in WT RBD-CBD and $77.6 \%$ to $40.2 \%$ (37.4\%, p<0.001) in alpha RBD-CBD between the two groups of samples (Fig 4D). Meanwhile a more substantial reduction was seen in beta $(47.8 \%, p<0.0001)$, gamma $(49.5 \%, p<0.001)$ and delta variant $(53.5 \%, p<0.0001)$ respectively (Fig 4D). It is interesting to observe the stark decline

301 of nAb blocking for delta variant in the post 3 months cohort especially when no 
medRxiv preprint doi: https://doi.org/10.1101/2021.11.11.21266241; this version posted November 14,2021 . The copyright holder for this preprint (which was not certified by peer review) is the author/funder, who has granted medRxiv a license to display the preprint in

All rights reserved. No reuse allowed without permission.

302

303

304

305

306

307

308

309

310

311

312

313

314

315

316

317

318

319

320

321

322

323

324

325

326

327

328

329

330

331

332

333

334

335

significant difference of nAb response was detected from WT for samples vaccinated within 3 months (Fig 4A). The modified cpVNT results agree with recent findings where BNT162b2 vaccine induced protection wanes within 4-5 months especially against the delta variant despite earlier findings suggest effective neutralization 19,20. This demonstrates that this test can be effectively adapted in the event of future VOC emergence to quickly assess vaccinees' responses and even to identify vulnerable individuals for booster shots to prevent breakthrough infections.

\section{DISCUSSION}

The rapid modified cpVNT can improve our understanding of the relationship between $\mathrm{nAb}$ response and RDB/ACE2 interaction, especially in response to emerging and predictive mutants. Given the complex innate and cell mediated immune response against infection and immune-protection development, factors like synergistic mutations and epitope remodelling to prevent $\mathrm{nAb}$ recognition are key to a variant's immune escape characteristics ${ }^{21}$. We tested the influence of RBD/ACE2 interaction on nAb blocking with the hypothetical AD variant that carries N501Y T478K mutation. It was found unable to evade vaccine induced $\mathrm{nAb}$ inhibition where it shows $91.8 \%$ $\mathrm{nAb}$ blocking in the modified cpVNT similar to WT RBD-CBD despite its high affinity to ACE2 (Fig S4B). Since a single T478K mutation did not present compromising effect on the binding of potent neutralizing mAbs previously ${ }^{22}$, we observed that the additional N501Y mutation in AD variant does not affect nAb binding within the modified cpVNT's reaction time (Fig S4B). In contrast, the beta variant despite showing modest increase in affinity towards ACE2 (KD 9.6 nM) than WT (KD $12.7 \mathrm{nM})$, exhibited significantly lower nAb percent blocking than WT (Fig. 4A). As the K417 and E484 sites are known to escape both class 1 and class 2 anti-RBD antibodies ${ }^{23}$, the combined effect of RBD/ACE2 binding and poor nAb recognition generate more pronounced immune escape response. These examples indicate that the modified cpVNT can be used to systematically assess the RBD mutations and improve our understanding of its underlying molecular mechanism versus nAb response.

With the emergence of highly transmissible SARS-CoV-2 variants, the durability and persistence of vaccine effectiveness is of major concern. Although nAb response strongly correlates with immune protection ${ }^{12}$, cellular immunity is essential in providing sustained immune protection upon exposure, particularly against severe illness. 
medRxiv preprint doi: https://doi.org/10.1101/2021.11.11.21266241; this version posted November 14,2021 . The copyright holder for this preprint (which was not certified by peer review) is the author/funder, who has granted medRxiv a license to display the preprint in

All rights reserved. No reuse allowed without permission.

336 Therefore, both humoral and cellular immune response are required for a complete

337 assessment of SARS-CoV-2 immunity. While standardized methods for rapid

338 assessment of cellular immunity responses are underway ${ }^{24}$, nAb level measurement

339 remains a reliable indicator for immune-protection at $\mathrm{PoC}$ level and deems to be critical

340 at this point. It has been estimated that $90 \%$ of convalescent plasma/sera's

341 neutralizing activity targets the immunodominant RBD ${ }^{25-27}$, hence the current

342 modified cpVNT format that measures the nAb response to RBD-associated mutations

343 represents a good proxy for assessing individual's immune protection. The

344 standardized percent blocking provided by the customized reader, permits consistent

345 results interpretation as opposed to colorimetric scoring. Besides, as demonstrated

346 here, the test only requires a simple change in one reagent while retaining the test

347 format, instrumentation, and capability to evaluate $n A b$ responses to a new variant.

348 This feature is quintessential for keeping up with the rapidly evolving virus, for example

349 the new mu variant in Colombia that was reported to escape vaccine induced immunity

35028 .

351

352 Our data also shows the strength of the modified cpVNT as a PoC test to provide 353 insights on the deteriorating vaccine efficacy observed globally against the delta 354 variant and the climbing breakthrough infections among vaccinated population. The 355 significant decline of nAb response against the delta variant observed among post 3 356 months's BNT162b2 vaccinees in our study provides a possible reason for the 357 increased breakthrough infections observed globally. The report that BNT162b2 358 recipients who completed their vaccination between Jan-April in Israel had an 359 increased risk of breakthrough infections with delta variant is in line with our 360 interpretation ${ }^{29}$. Thus, our test's ability to detect variant specific nAb waning effects 361 among a vaccinated population provides an extremely valuable tool to pre-emptively 362 test $n A b$ responses against emerging variants and through this inform booster 363 planning and public health management.

\section{MATERIALS AND METHODS}

\subsection{Study participants}

Heathy adults age between 21-65 years old scheduled for Singapore national vaccination program were enrolled to the study in compliance with all relevant ethical regulations and was approved by Institutional Review Board of Nanyang 
medRxiv preprint doi: https://doi.org/10.1101/2021.11.11.21266241; this version posted November 14,2021 . The copyright holder for this preprint (which was not certified by peer review) is the author/funder, who has granted medRxiv a license to display the preprint in

All rights reserved. No reuse allowed without permission.

370 Technological University (IRB-2021-04-020). All participants provided informed 371 consent before participation under voluntary basis and reported with no prior SARS-

372 CoV-2 infection at point of recruitment. The venous blood collection was performed by 373 certified phlebotomists while finger-prick blood was collected using Haim ${ }^{\circledR}$ Winnoz 374 blood collection device or manual collection. Pre-SARS-CoV-2 plasma samples were collected under IRB 003/2010, IRB 11/08/03, IRB 13/09/01 and IRB-2016-01-045 stored in $-80^{\circ} \mathrm{C}$. Whole-blood samples from healthy volunteers vaccinated more than 3 months was provided by National Centre of Infectious Diseases (NCID) under DSRB 2012/00917. There were no breakthrough infections reported from these samples.

\subsection{Blood sample processing and storage}

Blood samples were kept at $4^{\circ} \mathrm{C}$ for delivery, venous blood storage in heparin tubes (BD Vacutainer ${ }^{\circledR} \# 367874$ ) while finger stick blood were stored in either heparin (Xinle Medical MP0540) or EDTA (Xinle Medical MP0581) microtainer tubes. A portion of the sample volume was separated into plasma content by centrifugation at $4000 \mathrm{~g}$ for 5 minutes in $4^{\circ} \mathrm{C}$. Plasma were stored in $-20^{\circ} \mathrm{C}$. Both WHO International Standard (20/136) and Reference Panel for anti-SARS-CoV-2 immunoglobulin (20/268) plasma were purchased from National Institute for Biological Standards and Control (NIBSC, United Kingdom) and were stored in $-20^{\circ} \mathrm{C}$ upon receipt.

\subsection{Protein production and purification}

391 The expression and purification of soluble extracellular fragment of human ACE2 392 (residues 19-615; GenBank: AB046569.1) and wildtype (WT) SARS-CoV2-Spike 393 (EMBL: QHD43416.1 with silent mutations c.A1452>G and c.T1470>C) RBD fused to 394 CBD followed the same protocol as described in Kongsuphol et al. ${ }^{10}$. Similarly, alpha 395 c.A1501>T (p.N501Y), beta c.A1501>T, c.G1251>C, c.G1450>A (p.N501Y K417N 396 E484K), gamma c.A1501>T, c.A1250>C, c.G1450>A (p.N501Y K417T E484K), delta 397 c.T1355>G, c.C1433>A (p.L452R T478K), kappa c.T1355>G, c.G1450>C (p.L452R 398 E484Q), epsilon c.T1355>G (p.L452R), delta plus c.T1355>G, c.C1433>A, 399 c.G1450>A (p.L452R T478K K417N ), eta c.G1450>A (p.E484K), lambda c.T1355>A 400 c. T1469>C (p.L452Q, F490S) and AD c.A1501>T, c.C1433>A (p.N501Y T478K) 401 RBD-CBD variants were expressed in Expi293F cells (Thermo Fisher Scientific, 402 A1435101) according to the supplier's protocol. The purification protocol followed that 
medRxiv preprint doi: https://doi.org/10.1101/2021.11.11.21266241; this version posted November 14,2021 . The copyright holder for this preprint (which was not certified by peer review) is the author/funder, who has granted medRxiv a license to display the preprint in

All rights reserved. No reuse allowed without permission.

403 of WT RBD-CBD. In brief, the proteins were subjected to affinity chromatography with

404 Ni-NTA cartridges (Qiagen, 1046323) and size exclusion chromatography with HiLoad

405 16/60 Sephadex 200 (Cytiva) in 20 mM HEPES pH 7.5, $300 \mathrm{mM} \mathrm{NaCl}, 10 \%$ glycerol.

406 The His-MBP tag of RBD-CBD variants were removed by incubation with TEV

407 protease overnight in 1:40 mass ratio at $4^{\circ} \mathrm{C}$. The untagged proteins were further

408 purified by reverse affinity chromatography with HisPur-Ni-NTA resin in 20 mM HEPES

$409 \mathrm{pH}$ 7.5, $300 \mathrm{mM} \mathrm{NaCl}, 10 \mathrm{mM}$ Imidazole. Lastly, the purified RBD-CBD variants were

410 concentrated and stored in 20 HEPES pH 7.5, $300 \mathrm{mM} \mathrm{NaCl}, 10 \%$ glycerol and 0.5

$411 \mathrm{mM}$ TCEP at $-80^{\circ} \mathrm{C}$.

412

413 4.4 Fluorescence conjugation of monoFc-ACE2

414 Alexa Fluor ${ }^{\circledR} 594$ conjugation of monoFc-ACE2 was carried out by using Alexa Fluor ${ }^{\circledR}$

415594 Conjugation Kit (Fast) - Lightning-Link $®$ (abcam, ab269822). For each labeling

416 reaction, $100 \mu \mathrm{L}$ of $1 \mathrm{mg} / \mathrm{mL}$ of monoFc-ACE2 in Phosphate Buffer Saline (PBS) pH

4177.6 was mixed with $10 \mu \mathrm{L}$ of Modifier reagent. The $110 \mu \mathrm{L}$ of mixture was transferred

418 to Alexa Fluor ${ }^{\circledR} 594$ Conjugation Mix followed by 30 minutes incubation at room

419 temperature in the dark. Then, the reaction was stopped by adding $10 \mu \mathrm{L}$ of Quencher

420 reagent and for 15 minutes incubation in the dark. Finally, the labelled protein was

421 stored in aliquots of $5 \mu \mathrm{L}$ at $-80^{\circ} \mathrm{C}$ freezer before use.

422

$423 \quad 4.5$ Cellulose pulldown virus neutralization test (cpVNT)

424 Every testing cassette was assembled by using 1 layer of Whatman No. 1 425 chromatography paper (GE healthcare, \#3001-861) as cellulose test strip and 2 layers

426 of Whatman gel blotting paper, Grade GB005 (GE healthcare, \#10426981) as

427 absorbent pads into a cassette housing (Racer Technology Pte. Ltd.). Then, both the

428 test and control spots were blocked with $5 \mu \mathrm{L}$ of $5 \%$ Bovine Serum Albumin (BSA) in

$429 \mathrm{PBS} \mathrm{pH}$ 7.6. The control spot is further treated with $5 \mu \mathrm{L}$ of $5 \mu \mathrm{M}$ RBD-CBD before air-

430 dry. For each test, $20 \mu \mathrm{L}$ of venous or finger pricked whole blood sample was first 431 incubated with $20 \mu \mathrm{L}$ of $10 \mathrm{nM}$ RBD-CBD in PBS pH 7.6, 1\% BSA for 3 minutes. After 432 that, $40 \mu \mathrm{L}$ of $5 \mathrm{nM}$ Alexa Fluor594 labelled monoFc-ACE2 (ACE2-AF594) in PBS pH

$4337.6,1 \%$ BSA was added to the mixture and incubated for another 5 minutes. The final

$43480 \mu \mathrm{L}$ reaction was applied equally onto the test and control spot with $40 \mu \mathrm{L}$ for each.

435 Once sample was fully absorbed, both test and control spots were washed once with 
medRxiv preprint doi: https://doi.org/10.1101/2021.11.11.21266241; this version posted November 14,2021 . The copyright holder for this preprint (which was not certified by peer review) is the author/funder, who has granted medRxiv a license to display the preprint in

All rights reserved. No reuse allowed without permission.

436

437

438

439

440

441

442

443

444

445

446

447

448

449

450

451

452

453

454

455

456

457

458

459

460

461

462

463

464

465

466

467

468

$40 \mu \mathrm{L}$ of PBS pH 7.6. The cassette was then placed in an Atto Testbed for fluorescence measurement. All steps described above were performed at room temperature.

\subsection{Fluorescence Measurement and Percent Blocking calculation}

The Atto Testbed (Attonics Systems Pte Ltd) comprised of an LED lamp (Thorlabs Inc., M590L4), Silicon Avalanche Photodiode detector (SiAPD) (Thorlabs Inc., APD440A) and mCherry filter set (Thorlabs Inc., MDF-MCHA) including an Excitation filter (578/21), an Emission filter (641/75) combined with a dichroic beam-splitter. The testbed was designed specifically to fit the testing cassette dimension for fluorescent signal detection. Fluorescence intensity was recorded as SiAPD output in $\mathrm{mV}$. The percent blocking was calculated using the Equation 1 (see Results section). All samples were tested in triplicates with their mean represented as single data point and the median percent blocking of each group with a given sample size was reported.

\subsection{Surrogate virus neutralization assay cPass (Genscript)}

The assay was performed as per manufacturer's protocol by first diluting the selected plasma samples 1:10 in the sample dilution buffer provided by the kit, and incubated with HRP-conjugated RBD for 30 minutes at $37^{\circ} \mathrm{C}$. Then, the sample-RBD mixtures were transferred to an ACE2 coated ELISA plate for 15 minutes incubation at $37^{\circ} \mathrm{C}$ before washing with the kit's washing solution. The sample read-out was performed by adding $100 \mu \mathrm{L}$ 3,3',5,5'-tetramethylbenzidine (TMB) solution per reaction well for 15 minutes, followed by $50 \mu \mathrm{L}$ of stop solution. Absorbance was measured at $450 \mathrm{~nm}$ using Infinite 200 PRO multimode TECAN plate reader and the percent of inhibition were calculated according to manufacturer's recommendation.

\subsection{Bio-layer Interferometry (BLI)}

The streptavidin biosensor tips (Sartoris) were pre-incubated with $20 \mathrm{nM}$ of the monoFc-ACE2, chemically biotinylated with EZ-link Sulfo-NHS-LC-Biotinylation kit (Thermo Fisher, \#21435). The binding of WT and all RBD-CBD variants were measured as optical thickness response for 600s of association phase followed by 900 s of dissociation phase. The concentration of RBD-CBDs were prepared in serial dilutions ranging from 3.125 - 100 nM (except for gamma RBD-CBD; 2.5 - $80 \mathrm{nM}$ ). Analysis of binding response was performed by Octet Data Analysis software using 
medRxiv preprint doi: https://doi.org/10.1101/2021.11.11.21266241; this version posted November 14,2021 . The copyright holder for this preprint (which was not certified by peer review) is the author/funder, who has granted medRxiv a license to display the preprint in All rights reserved. No reuse allowed without permission.

469

470

471

472

473

474

475

476

477

478

479

480

481

482

483

484

485

486

487

488

489

490

491

492

493

494

495

496

497

498

499

global 1:1 fitting for $K_{D}$ calculation. All experiments were performed using 8-channel Octet RED96e system (Forté Bio) in PBS, 0.2\% BSA and $0.05 \%$ Tween 20 at $25^{\circ} \mathrm{C}$.

\subsection{SARS-CoV-2 pseudovirus neutralization assay}

We applied the same protocol for production of SARS-CoV-2 pseudotyped lentiviral particles and pseudovirus neutralization assay as previously reported ${ }^{10}$. Briefly, to produce SARS-CoV-2 pseudovirus, HEK293T cells at $36 \times 10^{6}$ cell density were transfected with $27 \mu \mathrm{g}$ pMDLg/pRRE (Addgene, \#12251), $13.5 \mu \mathrm{g}$ pRSV-Rev (Addgene, \#12253), $27 \mu g$ pTT5LnX-WHCoV-St19 (SARS-CoV2 Spike) and $54 \mu \mathrm{g}$ pHIV-Luc-ZsGreen (Addgene, \#39196) using Lipofectamine 3000 (Invitrogen, \#L3000-150). Then the cells were grown for 3 days in $37^{\circ} \mathrm{C}, 5 \% \mathrm{CO}_{2}$ incubator. Harvested and filtered viral supernatant were concentrated and quantified by using Lenti-X p24 rapid titer kit (Takara Bio, \#632200). Twenty pre and post vaccinated individual plasma were diluted to 1:80 titre with PBS and mixed with equal volume of pseudovirus to $50 \mu \mathrm{L}$ followed by $1 \mathrm{~h}$ incubation at $37^{\circ} \mathrm{C}$. The neutralization assay was performed by transferring the plasma-pseudovirus mixture to monolayered $\mathrm{CHO}$ ACE2 cells $\left(5 \times 10^{4}\right.$ cells) in $100 \mu \mathrm{L}$ of complete medium containing DMEM/high glucose with sodium pyruvate (Gibco, \#10569010), 10\% FBS (Hyclone, \# SV301160.03), 10\% MEM Non-essential amino acids (Gibco, \#1110050), 10\% geneticin (Gibco, \#10131035) and 10\% penicillin/streptomycin (Gibco, \#15400054). After 1hr incubation, $150 \mu \mathrm{L}$ of complete medium were added for subsequent $48 \mathrm{hr}$ infection. Each plasma samples were tested in triplicates. The read-out was performed on Tecan Spark 100M after luciferase assay with ONE-glo ${ }^{\mathrm{TM}} \mathrm{EX}$ reagent (Promega, \#E8130) where the percent of neutralization was determined by:

Neutralization $\%=\frac{\text { Readout (unknown)-Readout } \text { (infected control) }}{\text { Readout (uninfected control)-Readout (infected control) }} * 100 \%$

\subsection{Statistical Analysis}

Neutralization antibody (nAb) response was represented by the median \% blocking in our results. Since we do not assume a normal distribution, a non-parametric KruskalWallis test with Dunn multiple comparison was performed for comparing Pre-Vac, post $1^{\text {st }}$ dose (1-3 weeks), post $1^{\text {st }}$ dose (3-6 weeks) and post $2^{\text {nd }}$ dose vaccination groups. Meanwhile two-sided Mann-Whitney test was performed for the two-group comparison 
medRxiv preprint doi: https://doi.org/10.1101/2021.11.11.21266241; this version posted November 14,2021 . The copyright holder for this preprint (which was not certified by peer review) is the author/funder, who has granted medRxiv a license to display the preprint in

All rights reserved. No reuse allowed without permission.

500 in analyzing between (i) BNT162b2 and mRNA-1273 post $1^{\text {st }}$ dose (3-6weeks)

501 vaccinated samples and (ii) nAb response within 3 months and post 3months cohorts.

502 The Friedman test with multiple comparison was performed for the same sample set

503 that repeated against RBD-CBD WT and the variants.

504

505

\section{ACKNOWLEDGEMENTS}

506 We thank all the IRB-2021-04-020 and DSRB 2012/00917 volunteers for their

507 participation throughout the study. We are grateful for the phlebotomists from National

508 University Hospital, NUS Occupational Health Clinic and Fullerton Healthcare @ NTU

509 for their assistance. The pHLmMBP-10 vector used in the cloning of WT and variant

510 RBD-CBDs was a gift of Luca Jovine, Department of Biosciences and Nutrition,

511 Karolinska Institutet, Sweden. Meanwhile, the TEV protease was a kind gift of NTU

512 Protein Production Platform (proteins.sbs.ntu.edu.sg). We thank Assoc Prof. Tan Yee

513 Joo, Department of Microbiology and Immunology, Yong Loo Lin, School of Medicine,

514 National University of Singapore (NUS) for the CHO-ACE2 stable cell line and SARS-

515 CoV-2 S protein plasmid for the pseudotyped lentiviral particle production. We also

516 greatly appreciate Prof. Herbert Moser and Dr. Felix Neugart from Attonics Inc. for

517 their scientific input. This study is supported by National Health Innovation Singapore

518 (NHIC) grant \# NHIC-COVID19-2005004, National Research Foundation via CREATE

519 Share grant \#R571-002-021-592 and the Antimicrobial Resistance Interdisciplinary

520 Research Group (AMR-IRG) of Singapore -MIT Alliance in Research and Technology

521 (SMART). All samples acquired from National Centre of Infectious Diseases (NCID)

522 were supported by Singapore Ministry of Health's National Medical Research Council

523 COVID-19 Research Fund: COVID19RF-0008.

524

\section{AUTHOR CONTRIBUTIONS}

526 S.M.L., H.L.C., H.J., P.K., conceived and designed the experimental study. H.J. and

527 P.K. supervised the method development. H.L.C. and S.M.L. performed modified 528 cpVNT experiments and analyzed the data. S.M.L. wrote the manuscript. B. S. 529 performed the pVNT assays. M.W.C. produced the recombinant proteins. S.Y.N 530 prepared the cassettes and cellulose papers. X.G. prepared IRB application and 531 obtained the IRB approval. S.P.T. and S.F.H. designed and developed the portable 532 reader device. J.S., S.S. and B.E.Y. provided the post 3 months vaccinated blood 533 samples. D.M.Y.T edited the manuscript. B.E.Y. M.E.M, H.D.S, P.A.M, P.R.P 
medRxiv preprint doi: https://doi.org/10.1101/2021.11.11.21266241; this version posted November 14,2021 . The copyright holder for this preprint (which was not certified by peer review) is the author/funder, who has granted medRxiv a license to display the preprint in

All rights reserved. No reuse allowed without permission.

534 contributed to the discussion, interpretation of the results and revision of the final

535 manuscript.

536

\section{CONFLICT OF INTEREST}

538 PK, MM, HDS, JH and PRP are the cofounders of Thrixen Pte Ltd, a start-up company working in further developing some of the technology presented here.

\section{REFERENCES}

542 1. Bergwerk M, Gonen T, Lustig Y, et al. Covid-19 Breakthrough Infections in Vaccinated Health Care Workers. N Engl J Med. 2021;385:1474-1484. doi:10.1056/NEJMOA2109072

2. Callaway E. COVID vaccine boosters: the most important questions. Nature. 2021;596(7871):178-180. doi:10.1038/d41586-021-02158-6

3. Kamar N, Abravanel F, Marion O, Couat C, Izopet J, Del Bello A. Three Doses of an mRNA Covid-19 Vaccine in Solid-Organ Transplant Recipients. N Engl J Med. 2021;385(7):661-662. doi:10.1056/nejmc2108861

4. Oguntuyo KY, Stevens CS, Hung CT, et al. Quantifying absolute neutralization titers against sars-cov-2 by a standardized virus neutralization assay allows for cross-cohort comparisons of covid-19 sera. MBio. 2021;12(1):1-23. doi:10.1128/mBio.02492-20

5. Gundlapalli A V., Salerno RM, Brooks JT, et al. SARS-CoV-2 serologic assay needs for the next phase of the US COVID-19 pandemic response. Open Forum Infect Dis. 2021;8(1). doi:10.1093/ofid/ofaa555

6. Tan CW, Chia WN, Qin X, et al. A SARS-CoV-2 surrogate virus neutralization test based on antibody-mediated blockage of ACE2-spike protein-protein interaction. Nat Biotechnol. 2020;38(9):1073-1078. doi:10.1038/s41587-0200631-z

7. Sancilio AE, D'aquila RT, Mcnally EM, et al. A surrogate virus neutralization test to quantify antibody-mediated inhibition of SARS-CoV-2 in finger stick dried blood spot samples. Sci Rep. 123;11:15321. doi:10.1038/s41598-021-94653-Z

8. Whitman JD, Hiatt J, Mowery CT, et al. Evaluation of SARS-CoV-2 serology assays reveals a range of test performance. Nat Biotechnol. doi:10.1038/s41587-020-0659-0

567 9. Wang JJ, Zhang N, Richardson SA, Wu J V. Rapid lateral flow tests for the 
medRxiv preprint doi: https://doi.org/10.1101/2021.11.11.21266241; this version posted November 14,2021 . The copyright holder for this preprint (which was not certified by peer review) is the author/funder, who has granted medRxiv a license to display the preprint in

All rights reserved. No reuse allowed without permission.

568

569

570

571

572

573

574

575

576

577

578

579

580

581

582

583

584

585

586

587

588

589

590

591

592

593

594

595

596

597

598

599

600

601

detection of SARS-CoV-2 neutralizing antibodies. Expert Rev Mol Diagnostic. 2021;21(4):363-370. doi:10.1080/14737159.2021.1913123

10. Kongsuphol $\mathrm{P}$, Jia $\mathrm{H}$, Cheng $\mathrm{HL}$, et al. A rapid simple point-of-care assay for the detection of SARS-CoV-2 neutralizing antibodies. Commun Med. doi:10.1038/s43856-021-00045-9

11. Mattiuzzo G, Bentley EM, Hassall M, et al. Establishment of the WHO International Standard and Reference Panel for anti-SARS-CoV-2 antibody. WHO Expert Comm Biol Stand. Published online 2020. WHO/BS/2020.2403

12. Khoury DS, Cromer D, Reynaldi A, et al. Neutralizing antibody levels are highly predictive of immune protection from symptomatic SARS-CoV-2 infection. Nat Med. 2021;27:1205-1211. doi:10.1038/s41591-021-01377-8

13. Gobeil SMC, Janowska K, McDowell S, et al. Effect of natural mutations of SARS-CoV-2 on spike structure, conformation, and antigenicity. Science (80- ). 2021;373(641). doi:10.1126/science.abi6226

14. Laffeber C, de Koning K, Kanaar R, Lebbink JHG. Experimental Evidence for Enhanced Receptor Binding by Rapidly Spreading SARS-CoV-2 Variants. J Mol Biol. 2021;433(15):167058. doi:10.1016/j.jmb.2021.167058

15. Zhu X, Mannar D, Srivastava SS, et al. Cryo-electron microscopy structures of the N501Y SARS-CoV-2 spike protein in complex with ACE2 and 2 potent neutralizing antibodies. PLOS Biol. 2021;19(4):1-17. doi:10.1371/journal.pbio.3001237

16. Wilfredo Garcia-Beltran AF, Lam EC, St Denis K, John lafrate A, Naranbhai V, Balazs Correspondence AB. Multiple SARS-CoV-2 variants escape neutralization by vaccine-induced humoral immunity. Cell. 2021;184:2372-2383. doi:10.1016/j.cell.2021.03.013

17. Pegu A, O'Connell S, Schmidt SD, et al. Durability of mRNA-1273 vaccineinduced antibodies against SARS-CoV-2 variants. Science. 2021;373(6561):1372-1377. doi:10.1126/science.abj4176

18. Bates TA, Leier HC, Lyski ZL, et al. Neutralization of SARS-CoV-2 variants by convalescent and BNT162b2 vaccinated serum. Nat Commun. 2021;12(5135). doi:10.1038/s41467-021-25479-6

19. Liu J, Liu Y, Xia H, et al. BNT162b2-elicited neutralization of B.1.617 and other SARS-CoV-2 variants. Nature. 2021;596(7871):273-275. doi:10.1038/s41586021-03693-y 
medRxiv preprint doi: https://doi.org/10.1101/2021.11.11.21266241; this version posted November 14,2021 . The copyright holder for this preprint (which was not certified by peer review) is the author/funder, who has granted medRxiv a license to display the preprint in

602

603

604

605

606

607

608

609

610

611

612

613

614

615

616

617

618

619

620

621

622

623

624

625

626

627

628

629

630

631

632

633

634

20. Pouwels KB, Pritchard E, Matthews P, et al. Effect of Delta on viral burden and vaccine effectiveness against new SARS-CoV-2 infections in the UK. Nat Med. Published online 2021. doi:10.1038/s41591-021-01548-7

21. Harvey WT, Carabelli AM, Jackson B, et al. SARS-CoV-2 variants, spike mutations and immune escape. Nat Rev Microbiol. 2021;19:409-424. doi:10.1038/s41579-021-00573-0

22. Liu C, Ginn HM, Dejnirattisai W, et al. Reduced neutralization of SARS-CoV-2 B.1.617 by vaccine and convalescent serum. Cell. 2021;184(16):4220-4236.e13. doi:10.1016/j.cell.2021.06.020

23. Greaney AJ, Starr TN, Barnes CO, et al. Mapping mutations to the SARS-CoV2 RBD that escape binding by different classes of antibodies. Nat Commun. 2021;12(1). doi:10.1038/s41467-021-24435-8

24. Tan AT, Lim JME, Bert N Le, et al. Rapid determination of the wide dynamic range of SARS-CoV-2 Spike T cell responses in whole blood of vaccinated and naturally infected. J Clin Invest. 2021;131(17). doi:10.1172/JCI152379.

25. Piccoli L, Park YJ, Tortorici MA, et al. Mapping Neutralizing and Immunodominant Sites on the SARS-CoV-2 Spike Receptor-Binding Domain by Structure-Guided High-Resolution Serology. Cell. 2020;183(4):1024-1042.e21. doi:10.1016/j.cell.2020.09.037

26. Robbiani DF, Gaebler C, Muecksch F, et al. Convergent antibody responses to SARS-CoV-2 in convalescent individuals. Nature. 2020;584(7821):437-442. doi:10.1038/s41586-020-2456-9

27. Shi $R$, Shan $C$, Duan $X$, et al. A human neutralizing antibody targets the receptor-binding site of SARS-CoV-2. Nature. 2020;584(7819):120-124. doi:10.1038/s41586-020-2381-y

28. Uriu, Keiya; Kimura, Azumi;Shirakawa, Kotaro; Takaori-Kondo, Akifumi ; Nakada, Taka-aki; Kaneda, Atsushi; Nakagawa, So; Sato K. Neutralization of the SARS-CoV-2 Mu variant by convalescent and Vaccine Serum. N Engl J Med. Published online 2021. doi:10.1056/NEJMc2114706

29. Mizrahi B, Lotan R, Kalkstein N, et al. Correlation of SARS-CoV-2 Breakthrough Infections to Time-from-vaccine. Nat Commun. 2021;12:6379. doi:10.1038/s41467-021-26672-3 
medRxiv preprint doi: https://doi.org/10.1101/2021.11.11.21266241; this version posted November 14,2021 . The copyright holder for this preprint (which was not certified by peer review) is the author/funder, who has granted medRxiv a license to display the preprint in

All rights reserved. No reuse allowed without permission.

635 TABLE 1: Binding kinetics of wildtype and RBD-CBD variant with biotinylated

636 ACE2

\begin{tabular}{llllrl}
\hline RBD & Lineage name & $\begin{array}{l}\text { Mutation on } \\
\text { RBD }\end{array}$ & $\begin{array}{l}\text { Binding } \\
\text { affinity, } \mathrm{K}_{\mathrm{D}} \\
\text { (nM) }\end{array}$ & ka (1/Ms) & kdis (1/s) \\
\hline WT & & 12.7 & 99200 & 0.00127 \\
\hline alpha & B.1.1.7 & N501Y & 8.17 & 122000 & 0.000997 \\
\hline beta & B.1.351 & N501Y, K417N, & 9.59 & 132000 & 0.00126 \\
\hline gamma & P.1 & E484K & & & \\
\hline delta & B.1.167.2 & L452R, T478K & 9.19 & 231000 & 0.0021 \\
\hline kappa & B.1.167.1 & L452R, E484Q & 22.2 & 70400 & 0.00156 \\
\hline epsilon & B.1.427/B.1.429 & L452R & 20.7 & 96900 & 0.002 \\
\hline delta plus & AY.1 & L452R, T478K, & 25.2 & 103000 & 0.0026 \\
& & K417N & & & 0.000954 \\
\hline eta & B.1.525 & E484K & 18.7 & 160000 & 0.0029 \\
\hline lambda & C.37 & L452Q, F490S & 26.1 & 93300 & 0.00244 \\
\hline AD & & N501Y, T478K & 3.01 & 153000 & 0.000459 \\
\hline & & & & & \\
\hline
\end{tabular}

637

638

639

640

641

642

643

644

645

646

647

648

649

650

651

652

653

\section{FIGURES LEGEND}

Fig. 1: Schematic of cpVNT workflow and results obtained with contrived wholeblood sample. A. Graphical representation of the modified cpVNT workflow before detection in fluorescent reader. B. Cartoon depicting of possible molecular events occur in samples with and without nAb on the test spot and reagent control spot. C. Measurement of fluorescence intensity from pre vaccination whole blood samples titrated with 1, 5, 10, 25, 50, 100 nM SARS-CoV-2 monoclonal neutralizing antibody (nAb) D. The percent blocking calculated from Equation 1 with nAb concentration presented in log scale.

Fig. 2: Evaluation of $n A b$ response among pre-vaccination and post-vaccinated individuals using modified cpVNT. A. The percent blocking measured from 170 whole blood samples of pre vaccination, Pre-Vac $(n=36)$, post $1^{\text {st }}$ dose $(1-2 \mathrm{~W} n=10$, $3-6 \mathrm{~W} n=50)$ and post $2^{\text {nd }}$ dose $(n=74)$. The grey line is the median from each group 
medRxiv preprint doi: https://doi.org/10.1101/2021.11.11.21266241; this version posted November 14,2021 . The copyright holder for this preprint (which was not certified by peer review) is the author/funder, who has granted medRxiv a license to display the preprint in

All rights reserved. No reuse allowed without permission.

654 while each dot represents the mean from three independent experiments. B. The nAb 655 percent blocking measured in individuals opt for BNT162b2 ( $n=4$ from P1 - 1-2W, $n=30$ 656 from $\mathrm{P} 1$ - 3-6W, $n=40$ from P2) or C. mRNA-1273 (P1 - 1-2W n=6; P1 - 3-6W n=20; 657 P2 $n=34)$. Kruskal-Wallis test with Dunn's multiple comparison was performed 658 between each vaccination status. D. Comparison of nAb percent blocking at P1 3-6W 659 BNT162b2 and P1 3-6W mRNA-1273. Two tailed Mann-Whitney test was performed 660 between the two vaccine brands. The significance values ${ }^{*} P<0.05$, ${ }^{* \star} P<0.01$, ${ }^{\star \star *} P$ $661<0.001,{ }^{\star \star \star \star} P<0.0001$. Total samples: Pre-Vac versus $\mathrm{P} 1-3-6 \mathrm{~W}, P<0.001$; Pre662 Vac versus $P 2, P<0.0001$. BNT162b2: Pre-Vac versus $P 1-3-6 \mathrm{~W}, P<0.05$; Pre-Vac 663 versus $P 2, P<0.0001$. mRNA-1273: Pre-Vac versus $P 1-3-6 \mathrm{~W}, P<0.001$; Pre-Vac 664 versus $P 2, P<0.0001$. E. Twenty-two individual samples percent blocking mapped 665 over pre and post vaccination period comparing between two types of vaccines, 666 BNT162b2 $n=12$, mRNA $1273 n=10$. The window period between first and second 667 dose of vaccination ranged from 4 to 6 weeks depending on individual's choice.

668

669 Fig. 3: Comparison of modified cpVNT with international standards and 670 established serology tests. A. The performance of the First WHO International 671 standard Anti-SARS-CoV-2 Immunoglobulin (20/136), Reference Panel for anti672 SARS-CoV-2 Mid-tire and Low-titre plasma using modified cpVNT. B. The correlation 673 of percent blocking measured from 30 matching plasma and blood samples at pre 674 vaccination (Pre-Vac), post $1^{\text {st }}$ dose (P1) and post $2^{\text {nd }}$ dose (P2) phase using modified 675 cpVNT gave Pearson $r, 0.908$. The percent blocking for $c p V N T$ with blood samples 676 that correspond to $1000 \mathrm{IU} / \mathrm{mL}, 220 \mathrm{IU} / \mathrm{mL}$ and $44 \mathrm{IU} / \mathrm{mL}$ are determined by assuming 677 a linear correlation between the two sample types (see accompanying table). C. 678 Comparison of percent blocking measured in the modified cpVNT with percent 679 inhibition of SVNT (cPass ${ }^{\mathrm{TM}}$ ) in 45 matching Pre-Vac, P1 and P2 venous blood and 680 plasma samples. The sensitivity was calculated as $81.5 \%(\mathrm{Cl}: 61.9-93.7 \%)$, and 681 specificity is $100 \%$ (Cl: $81.5-100 \%)$ when both cpVNT and sVNT's (cPass ${ }^{\mathrm{TM}}$ ) 682 thresholds were set at $30 \%$ blocking. D. Comparison between cpVNT and pseudovirus 683 neutralization test ( $p$ VNT) with 20 individuals' sample. The pVNT was performed with 684 plasma in 1:80 dilution. The sensitivity is $100 \%(\mathrm{Cl}: 47.8-99.9 \%)$ and specificity is $66.7 \%$ 685 (Cl: 38.4-88.2\%) with 30\% blocking as the threshold for cpVNT and 50\% neutralization 686 for pVNT. All experiments were performed in triplicates. 
medRxiv preprint doi: https://doi.org/10.1101/2021.11.11.21266241; this version posted November 14,2021 . The copyright holder for this preprint (which was not certified by peer review) is the author/funder, who has granted medRxiv a license to display the preprint in

All rights reserved. No reuse allowed without permission.

688 Fig. 4: Assessment of $\mathrm{nAb}$ response to variants of concern depending on 689 vaccine brand or time post vaccination with our modified cpVNT. A. Whole blood

690 samples $(n=39)$ from participants who completed vaccination within three months were 691 tested with wildtype (WT) RBD-CBD and variant RBD-CBD. Friedman test with 692 multiple comparison was performed comparing the variants against $\mathrm{WT},{ }^{*} P<0.05$, ${ }^{\star \star} P$ $693<0.01$, ${ }^{\star \star \star} P<0.001$, ${ }^{\star \star \star \star} P<0.0001$. WT versus alpha, $P<0.01$; WT versus beta, $P<$ $6940.0001 ;$ WT versus gamma, $P<0.0001$; WT versus delta, n.s. B. The percent blocking 695 of nAb measured from 20 P2 samples of BNT162b2 recipients ( $\leq 3$ months) when 696 tested with RBD-CBD variants C. Similarly, percent nAb blocking of 19 P2 samples ( $\leq$ 6973 months) from mRNA-1273 recipients tested with the RBD-CBD variants. $D$. The nAb 698 response in BNT16b2 recipients against WT and RBD-CBD variants when comparing 699 two groups: within three months $(n=20)$ and more than three months $(n=37)$ after 700 complete vaccination. Two-sided Mann Whitney test was performed between the two 701 groups for each variant, WT $P<0.0001$, alpha $P<0.001$, beta $P<0.0001$, gamma $P$ $702<0.001$, delta $P<0.0001$.

703 


\section{FIGURE 1}

A

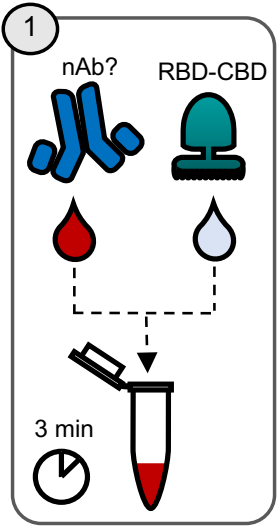

B

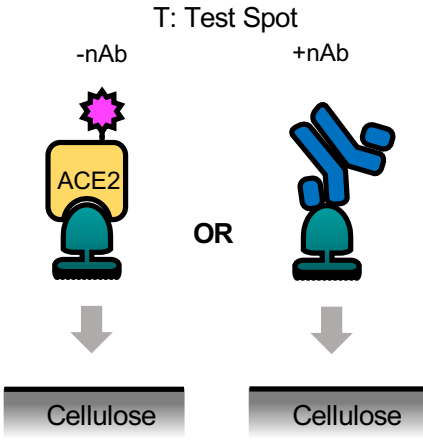

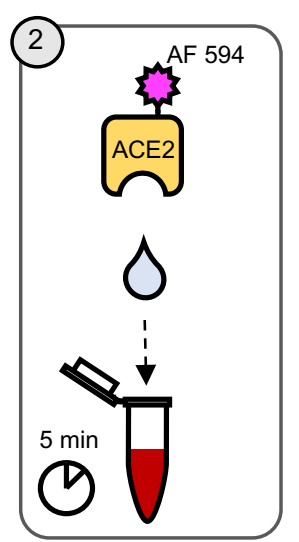

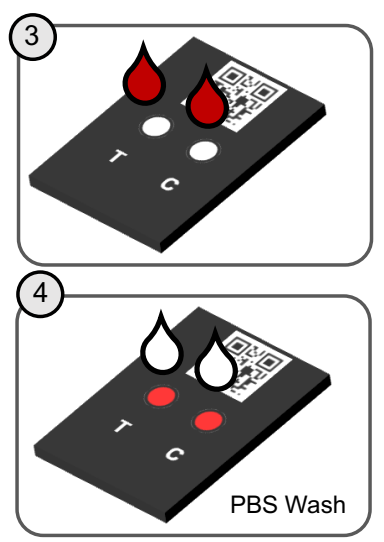

C: Reagent Control Spot

C

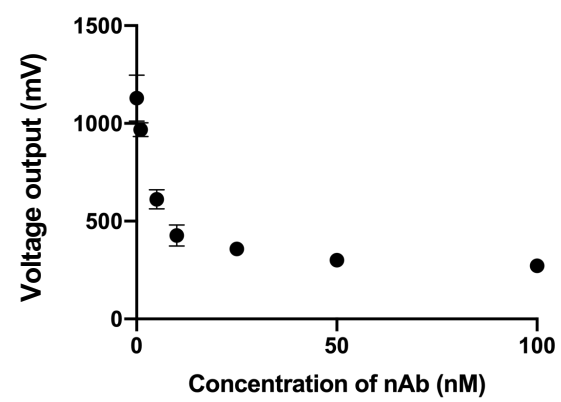

Eq.1

$\%$ Blocking $=\left(1-\frac{\text { Voltage output of test spot }- \text { Baseline }}{\text { Voltage output of Negative control }- \text { Baseline }}\right) \times 100 \%$

D

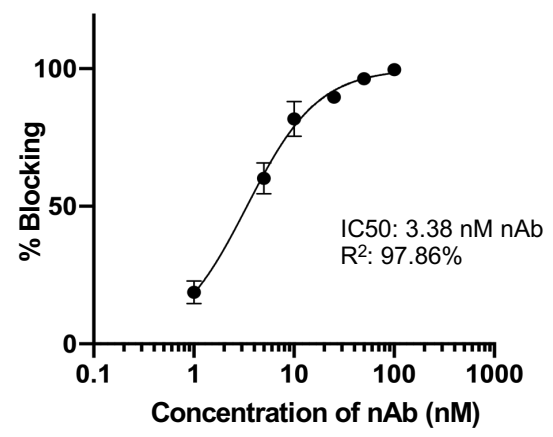

Schematic of cpVNT workflow and results obtained with contrived whole-blood sample.

A. Graphical representation of the modified cpVNT workflow before detection in fluorescent reader. B. Cartoon depicting of possible molecular events occur in samples with and without nAb on the test spot and reagent control spot. C. Measurement of fluorescence intensity from pre vaccination whole blood samples titrated with 1, 5, 10, 25, 50, $100 \mathrm{nM}$ SARS-CoV-2 monoclonal neutralizing antibody (nAb) D. The percent blocking calculated from Equation 1 with nAb concentration presented in log scale. 
A.

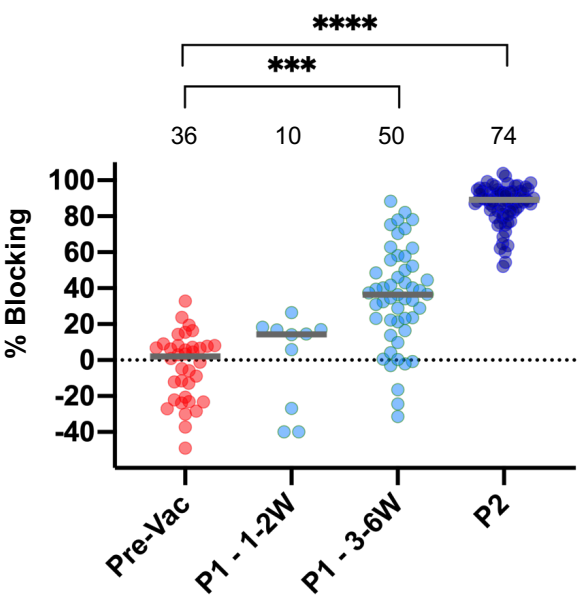

B.

BNT162b2
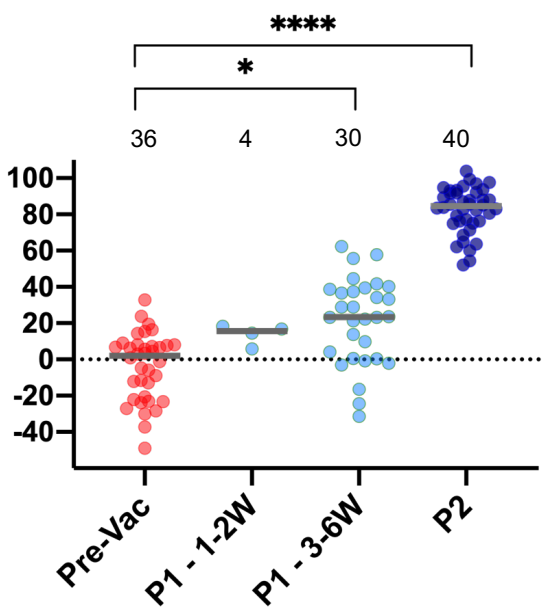

C.

mRNA-1273
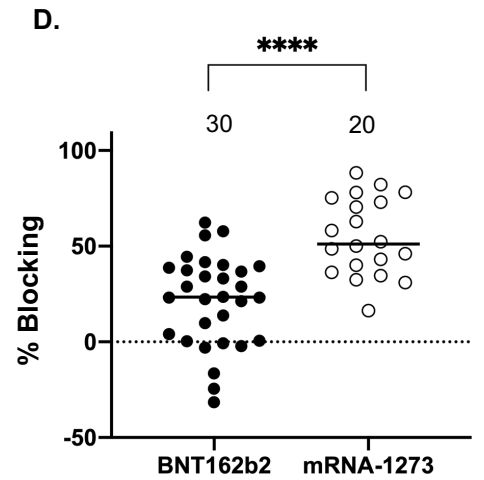

E.
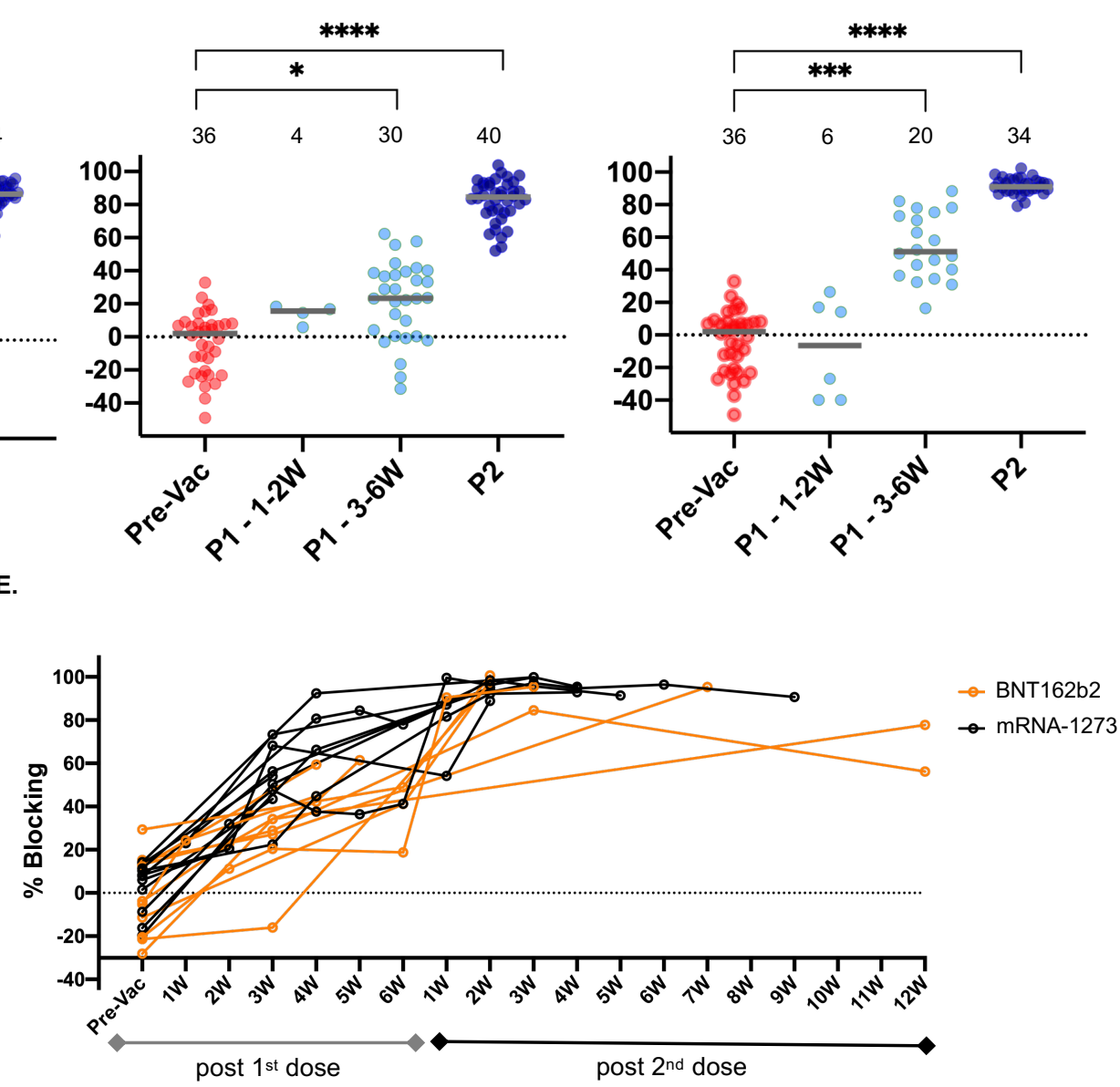

Evaluation of $\mathrm{nAb}$ response among pre-vaccination and post-vaccinated individuals using modified cpVNT.

A. The percent blocking measured from 170 whole blood samples of pre vaccination, Pre-Vac $(n=36)$, post 1 st dose $(1-2 \mathrm{~W} n=10,3-6 \mathrm{~W}$ $n=50)$ and post $2^{\text {nd }}$ dose $(n=74)$. The grey line is the median from each group while each dot represents the mean from three independent experiments. B. The $n A b$ percent blocking measured in individuals opt for BNT162b2 $(n=4$ from $P 1-1-2 W, n=30$ from $P 1-$ $3-6 W, n=40$ from $P 2)$ or C. mRNA-1273 (P1 - 1-2W n=6, P1 - 3-6W n=20, P2 n=34). Kruskal-Wallis test with Dunn's multiple comparison was performed between each vaccination status. D. Comparison of nAb percent blocking at P1 3-6W BNT162b2 and P1 36W mRNA-1273. Two tailed Mann-Whitney test was performed between the two vaccine brands. The significance values * $P<0.05$, ${ }^{*}$ * $P<0.01,{ }^{* * *} P<0.001,{ }^{* * *} P<0.0001$. Total samples: Pre-Vac versus $\mathrm{P} 1-3-6 \mathrm{~W}, P<0.001 ;$ Pre-Vac versus $\mathrm{P} 2, P<0.0001$. BNT162b2: Pre-Vac versus P1 - 3-6W, $P<0.05$; Pre-Vac versus $P 2, P<0.0001$. mRNA-1273: Pre-Vac versus $P 1-3-6 W, P<0.001$; Pre-Vac versus $P 2, P<0.0001$. E. Twenty-two individual samples percent blocking mapped over pre and post vaccination period comparing between two types of vaccines, BNT162b2 n=12, mRNA $1273 n=10$. The window period between first and second dose of vaccination ranged from 4 to 6 weeks depending on individual's choice. 


\section{FIGURE 3}

A
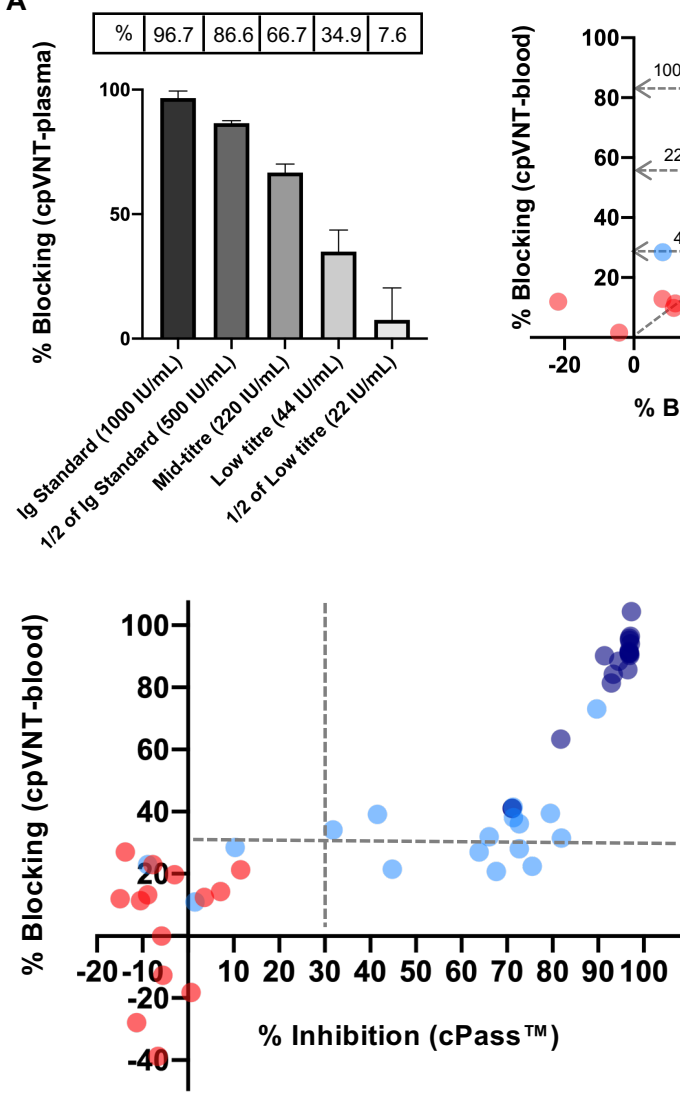

B

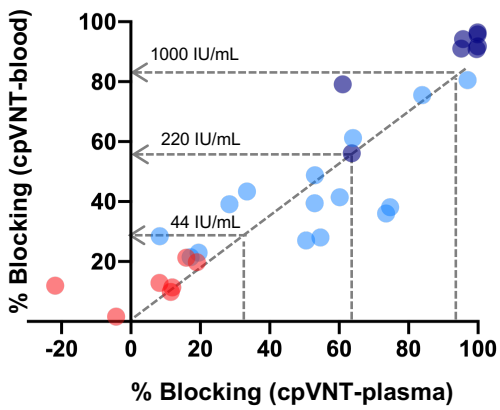

$\mathrm{P} 1$

P2

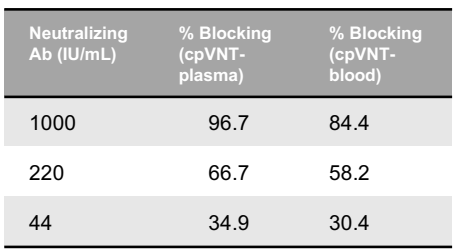

Pearson $r=0.908$

$\%$ blocking $($ blood $)=0.87 \%$ blocking $($ plasma $)$
D

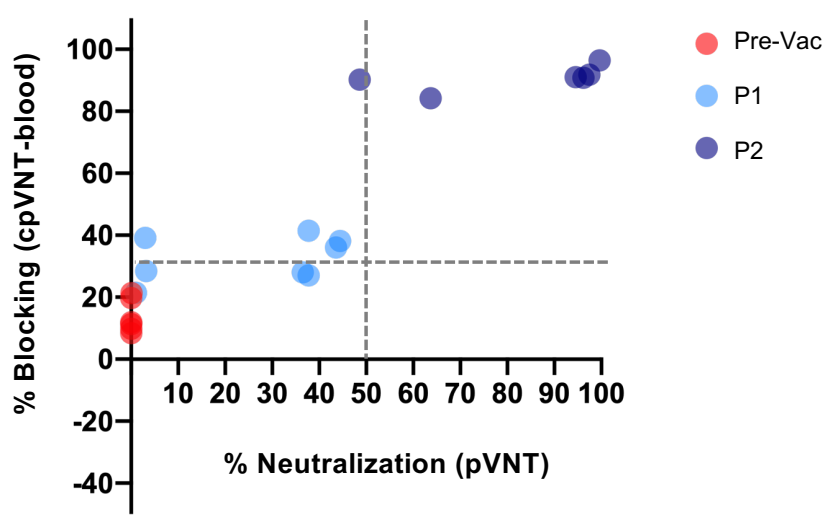

Comparison of modified cpVNT with international standards and established serology tests.

A. The performance of the First WHO International standard Anti-SARS-CoV-2 Immunoglobulin (20/136), Reference Panel for antiSARS-CoV-2 Mid-tire and Low-titre plasma using modified cpVNT. B. The correlation of percent blocking measured from 30 matching plasma and blood samples at pre vaccination (Pre-Vac), post $1^{\text {st }}$ dose (P1) and post $2^{\text {nd }}$ dose (P2) phase using modified $\mathrm{cpVNT}$ gave Pearson $r$, 0.908. The percent blocking for cpVNT with blood samples that correspond to $1000 \mathrm{IU} / \mathrm{mL}, 220 \mathrm{IU} / \mathrm{mL}$ and $44 \mathrm{IU} / \mathrm{mL}$ are determined by assuming a linear correlation between the two sample types (see accompanying table). C. Comparison of percent blocking measured in the modified cpVNT with percent inhibition of sVNT (cPass ${ }^{T M}$ ) in 45 matching Pre-Vac, P1 and P2 venous blood and plasma samples. The sensitivity was calculated as $81.5 \%(\mathrm{Cl}: 61.9-93.7 \%)$, and specificity is $100 \%(\mathrm{Cl}: 81.5-100 \%)$ when both cpVNT and sVNT's (cPass ${ }^{\mathrm{TM}}$ ) threshold were set at 30\% blocking. D. Comparison between cpVNT and pseudovirus neutralization test (pVNT) with 20 individuals' sample. The pVNT was performed with plasma in 1:80 dilution. The sensitivity is $100 \%(\mathrm{Cl}$ : $47.8-$ $99.9 \%$ ) and specificity is $66.7 \%$ (Cl: $38.4-88.2 \%)$ with $30 \%$ blocking as a threshold for cpVNT while $50 \%$ neutralization for pVNT. All experiments were performed in triplicates. 


\section{FIGURE 4}

A.

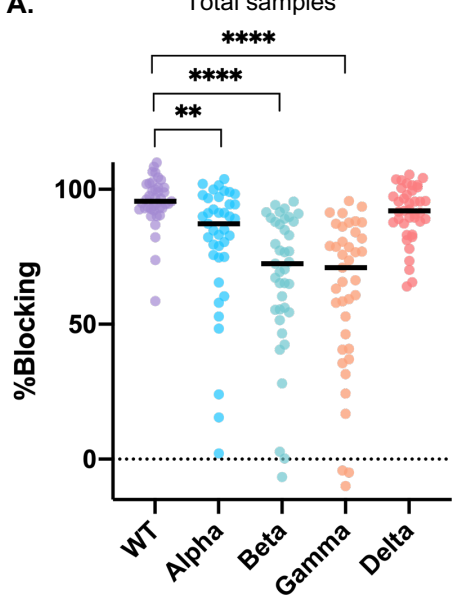

B.

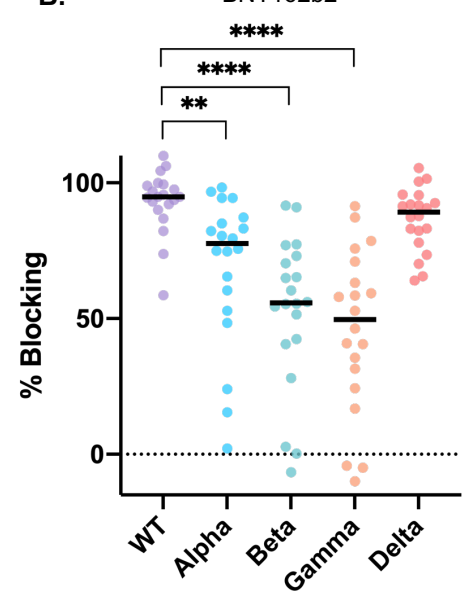

c.

mRNA-1273

D.

BNT162b2
WT
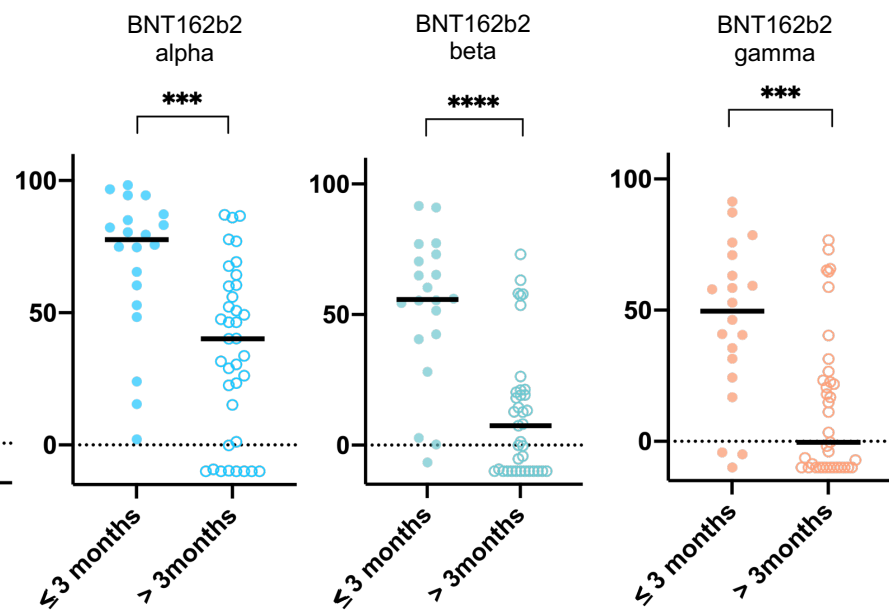

BNT162b2 delta
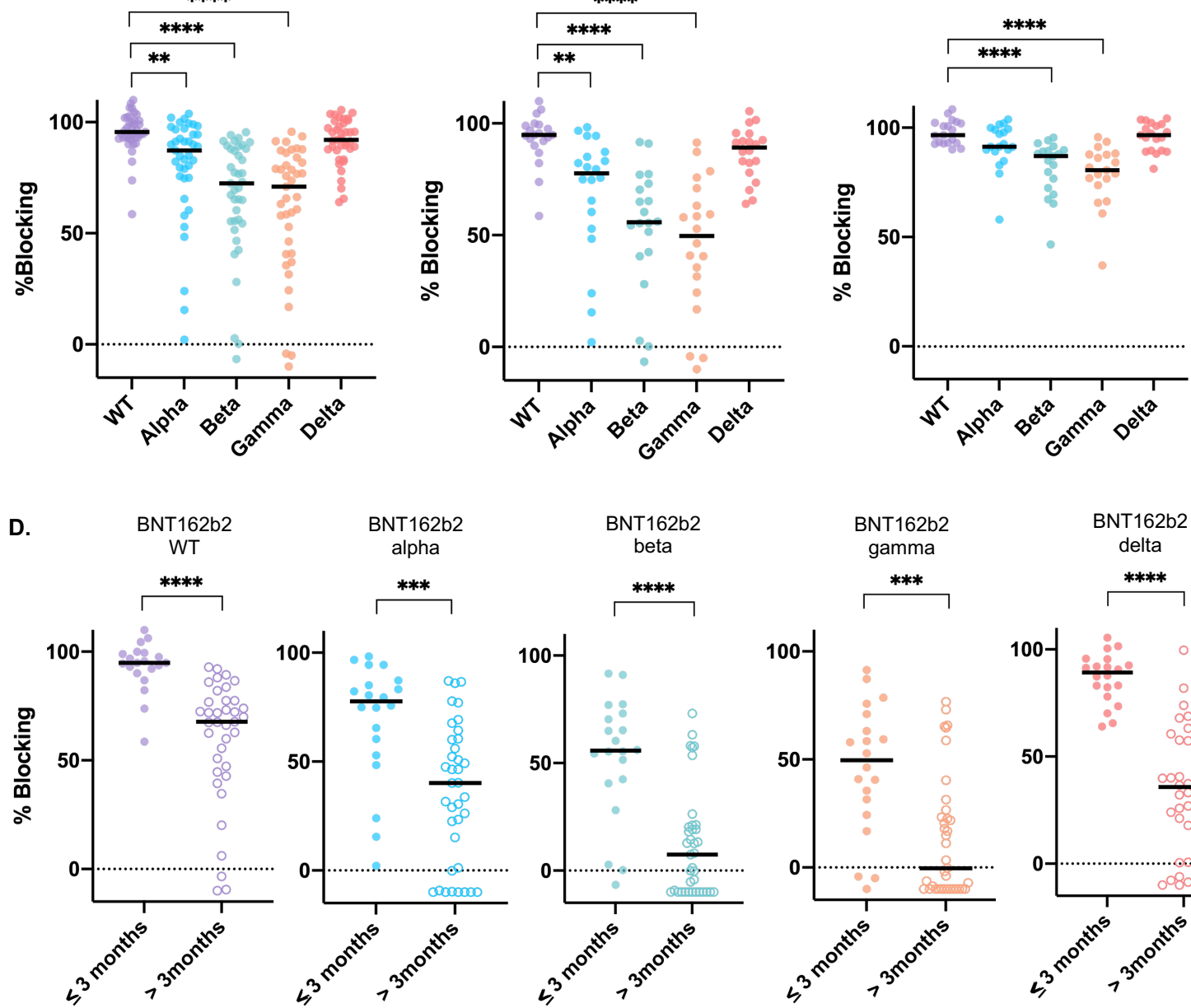